\title{
PRKAR1A mutation causing pituitary- dependent Cushing disease in a patient with Carney complex
}

\author{
Florian W Kiefer', Yvonne Winhofer', Donato lacovazzo², Márta Korbonits², \\ Stefan Wolfsberger ${ }^{3}$, Engelbert Knosp ${ }^{3}$, Franz Trautinger ${ }^{4}$, Romana Höftberger ${ }^{5}$, \\ Michael Krebs ${ }^{1}$, Anton Luger ${ }^{1}$ and Alois GessI ${ }^{1}$ \\ ${ }^{1}$ Clinical Division of Endocrinology and Metabolism, Department of Medicine III, Medical University of Vienna, \\ Vienna, Austria, ${ }^{2}$ Centre for Endocrinology, Barts and The London School of Medicine, Queen Mary University of \\ London, London, UK, ${ }^{3}$ Department of Neurosurgery, Medical University of Vienna, Vienna, Austria, ${ }^{4}$ Department of \\ Dermatology and Venereology, Karl Landsteiner University of Health Sciences, St Pölten, Austria, and ${ }^{5}$ Institute of \\ Neurology, Medical University of Vienna, Vienna, Austria
}

\author{
Correspondence \\ should be addressed \\ to A Gessl \\ Email \\ alois.gessl@meduniwien.ac.at
}

\section{Abstract}

Context: Carney complex (CNC) is an autosomal dominant condition caused, in most cases, by an inactivating mutation of the PRKAR1A gene, which encodes for the type 1 alpha regulatory subunit of protein kinase A. CNC is characterized by the occurrence of endocrine overactivity, myxomas and typical skin manifestations. Cushing syndrome due to primary pigmented nodular adrenocortical disease (PPNAD) is the most frequent endocrine disease observed in CNC. Case description: Here, we describe the first case of a patient with CNC and adrenocorticotropic hormone (ACTH)dependent Cushing disease due to a pituitary corticotroph adenoma. Loss-of-heterozygosity analysis of the pituitary tumour revealed loss of the wild-type copy of PRKAR1A, suggesting a role of this gene in the pituitary adenoma development.

Conclusion: PRKAR1A loss-of-function mutations can rarely lead to ACTH-secreting pituitary adenomas in CNC patients. Pituitary-dependent disease should be considered in the differential diagnosis of Cushing syndrome in CNC patients.

\section{Introduction}

Carney complex (CNC) is a syndrome characterized by spotty skin pigmentation, myxomas and endocrine abnormalities. Although several manifestations of this disease had been reported previously (1), Carney et al. were the first to describe CNC as a distinct entity in 1985 (2). Multiple lentigines are the most common presenting feature, and frequently affect distinct areas such as the lips, the conjunctiva and the vaginal or penile mucosa (3, 4). Myxomas can occur in various organs, particularly the heart, breast and skin. The most common endocrine disease observed in CNC is adrenocorticotropic hormone (ACTH)independent Cushing syndrome secondary to primary
(C) 2017 European Society of Endocrinology Printed in Great Britain pigmented nodular adrenocortical disease (PPNAD) (4). Other CNC-related endocrine disorders include growth hormone (GH) excess and hyperprolactinaemia secondary to pituitary tumours or hyperplasia, thyroid and testicular tumours, mostly represented by large cell-calcifying Sertoli cell tumours (LCCSCT) $(3,4)$.

In the majority of the cases, $\mathrm{CNC}$ is caused by inactivating mutations in the PRKAR1A gene (17q24.2) coding for the type 1 alpha regulatory subunit of the cAMP-dependent protein kinase A (PKA) (5). PKA plays a pivotal role in various cellular functions such as DNA replication, cell growth, proliferation and differentiation

Published by Bioscientifica Ltd. 
and is believed to act as a tumour suppressor gene via loss of the wild-type allele in affected tissues $(6,7)$. Most of the previously described PRKAR1A mutations lead to premature stop codons and subsequent degradation of the mutant mRNA by nonsense-mediated mRNA decay (8). Inactivating PRKAR1A mutations result in excess PKA signalling in affected tissues driving the tumorigenic process $(7,9)$.

\section{Case presentation and results}

A 31-year-old man presented at our Endocrine Clinic with typical signs of Cushing syndrome. His physical examination revealed moon face, abdominal obesity, skin atrophy and pronounced red striae on the abdomen, upper arms and thighs; body mass index was $27.1 \mathrm{~kg} / \mathrm{m}^{2}$. He had multiple junctional nevi, particularly on his torso. His previous medical history included surgical removal of the left testicle due to a large cell calcifying Sertoli cell tumour at the age of four and pilonidal sinus surgery at the age of 24 . At the age of 25 , the patient suffered a syncope while playing soccer. Echocardiography revealed myxomas in both atria with a $3 \times 5 \mathrm{~cm}$ left atrial myxoma protruding through the mitral valve, which necessitated surgical removal. His appearances and previous clinical history were highly suggestive of $\mathrm{CNC}(2,3)$.

The laboratory work-up revealed markedly elevated urinary free cortisol $(769 \mu \mathrm{g} / 24 \mathrm{~h}$, reference: 2.5$213.7 \mu \mathrm{g} / 24 \mathrm{~h})$ and increased basal ACTH $(106 \mathrm{pg} / \mathrm{mL}$, $23.3 \mathrm{pmol} / \mathrm{L}$, reference: $<46 \mathrm{pg} / \mathrm{mL},<10.1 \mathrm{pmol} / \mathrm{L}$; CLIA, Siemens Immulite2000). Morning serum cortisol was $11.4 \mu \mathrm{g} / \mathrm{dL}$ (314 nmol/L, reference: $<1.8 \mu \mathrm{g} / \mathrm{dL}, 50 \mathrm{nmol} / \mathrm{L})$ after a $1 \mathrm{mg}$ overnight dexamethasone suppression test. Consecutive low- and high-dose dexamethasone suppression tests $(4 \times 0.5 \mathrm{mg}$ dexamethasone daily for two days followed by $4 \times 2 \mathrm{mg}$ dexamethasone for two more days) did not result in adequate suppression of morning serum cortisol levels (basal: $24.2 \mu \mathrm{g} / \mathrm{dL}$ (668 nmol/L), after $48 \mathrm{~h}: 14.0 \mu \mathrm{g} / \mathrm{dL}(386 \mathrm{nmol} / \mathrm{L})$, after $96 \mathrm{~h}: 19.0 \mu \mathrm{g} / \mathrm{dL}$
$(524 \mathrm{nmol} / \mathrm{L}))$. Corticotropin-releasing hormone (CRH) test failed to further stimulate his already elevated ACTH levels. The rest of his pituitary function tests were normal. These results were consistent with ACTH-dependent Cushing syndrome but not with PPNAD, a form of ACTHindependent Cushing syndrome commonly observed in CNC patients $(3,10)$. Due to the lack of cortisol suppression following the high-dose dexamethasone suppression test and the absence of ACTH increase following $\mathrm{CRH}$ administration, we suspected ectopic ACTH production as the reason for hypercortisolism in this patient. Subsequent ${ }^{18} \mathrm{~F}$-fluorodeoxyglucose $\left({ }^{18} \mathrm{~F}-\mathrm{FDG}\right)$ positron emission tomography combined with computed tomography (PET/ CT) as well as ${ }^{18} \mathrm{~F}$-dihydroxyphenylalanine $\left({ }^{18} \mathrm{~F}\right.$-DOPA) PET/ CT did not show any lesions that would have qualified as a source for ectopic ACTH production. Therefore, inferior petrosal sinus (IPS) sampling was performed and showed a significant central to periphery ACTH ratio as well as lateralization to the left (Table 1), strongly suggesting the pituitary as the origin of the autonomous ACTH production. Magnetic resonance imaging (MRI) of the sellar region showed a $4 \times 6 \mathrm{~mm}$ left paramedian lesion, compatible with a pituitary microadenoma (Fig. 1A and B), whereas MRI of the adrenal glands was unremarkable. The left paramedian pituitary tumour was resected by transsphenoidal surgery, and histopathology confirmed a corticotroph adenoma with a Ki-67 labelling index of 7\% (Fig. 1C and E). Immunohistochemistry for ACTH was positive (Fig. 1D), while other pituitary hormones, including $\mathrm{GH}$ and prolactin were not expressed within the tumour. Following surgery, morning ACTH was $6.0 \mathrm{pg} / \mathrm{mL}(1.32 \mathrm{pmol} / \mathrm{L})$ and serum cortisol was $4.1 \mu \mathrm{g} /$ dL $(113 \mathrm{nmol} / \mathrm{L})$. Due to mild symptoms of adrenal insufficiency, the patient received low-dose hydrocortisone replacement (10 mg/day). In addition, the clinical signs of Cushing syndrome regressed over time, in keeping with disease remission. More than seven years after surgery, the patient remains free of signs and symptoms suggestive of a relapse of hypercortisolism.

Table 1 Inferior petrosal sinus sampling (IPS) results.

\begin{tabular}{|c|c|c|c|c|c|c|}
\hline \multirow[t]{2}{*}{ Location } & \multicolumn{2}{|c|}{ IPS right } & \multicolumn{2}{|c|}{ IPS left } & \multicolumn{2}{|c|}{ Periphery } \\
\hline & ACTH & Cortisol & ACTH & Cortisol & ACTH & Cortisol \\
\hline$-5 \mathrm{~min}$ & 381 (83.9) & $21.4(590)$ & 608 (134) & $20.5(566)$ & 64 (14.1) & $19.5(538)$ \\
\hline $0 \mathrm{~min}$ & 382 (84.1) & $22.7(626)$ & 940 (207) & $22.9(632)$ & $62(13.6)$ & $21.4(590)$ \\
\hline $5 \mathrm{~min}$ & $315(69.4)$ & $22.8(629)$ & 1302 (287) & $22.1(610)$ & 63 (13.9) & $20.3(560)$ \\
\hline $10 \mathrm{~min}$ & $273(60.1)$ & $22.5(621)$ & 840 (185) & $21.4(590)$ & $25(5.5)$ & $21.6(596)$ \\
\hline
\end{tabular}

By intravenous catheter technique, ACTH (pg/mL, pmol/L in parenthesis) and cortisol levels ( $\mu \mathrm{g} / \mathrm{dL}, \mathrm{nmol} / \mathrm{L}$ in parenthesis) were measured before and after $100 \mu \mathrm{g}$ ovine $\mathrm{CRH}$ administration in the right and left IPS as well as in the periphery. A significant central to periphery ratio (15.2 at time 0 ) was shown as well as lateralization to the left (left to right IPS ratio 2.5 at time 0 ). 

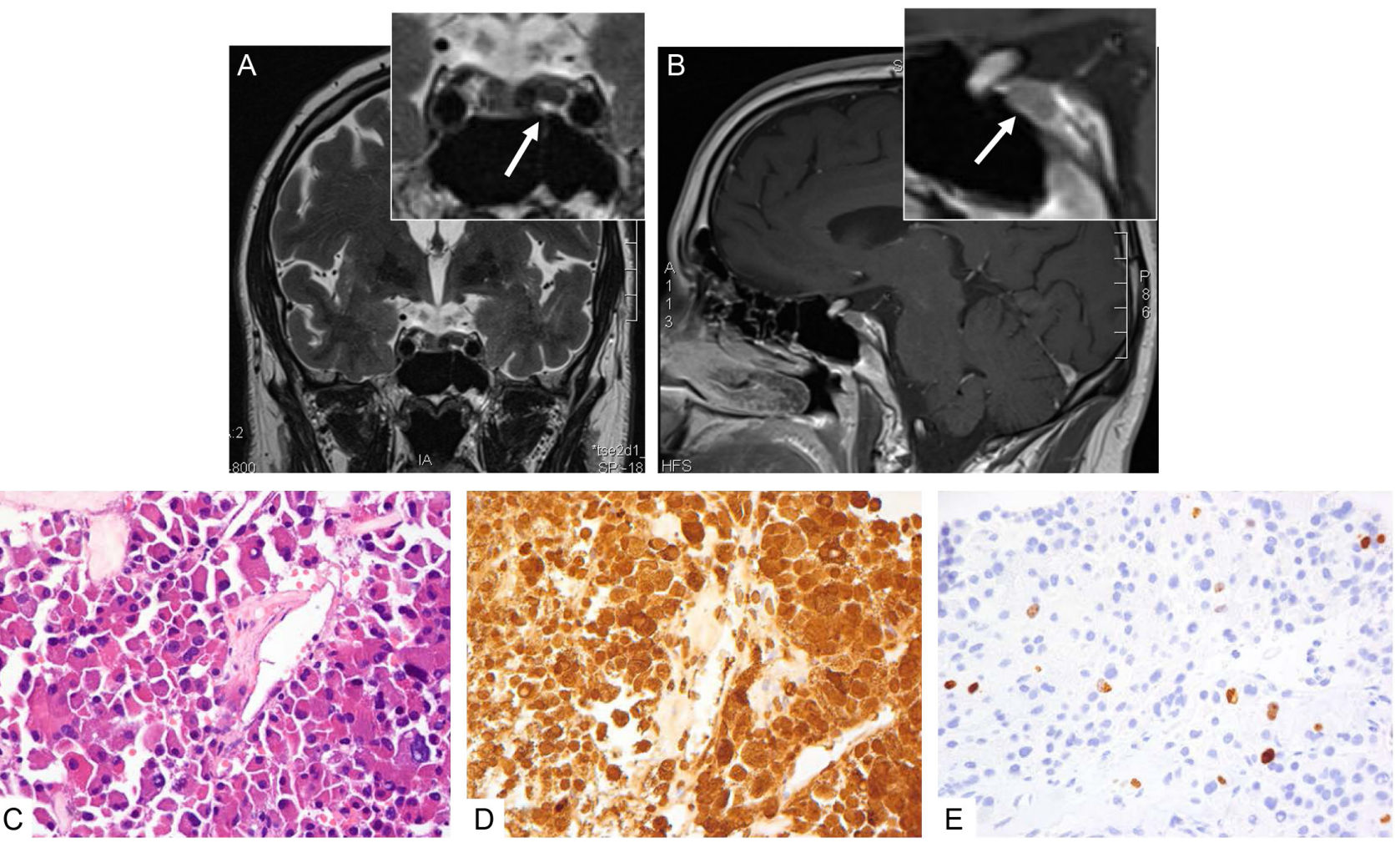

Figure 1

MRI images of the brain showing a left-sided pituitary microadenoma (arrows) on coronal (A) and sagittal (B) views. Histological and immunohistochemical staining of the tumour shows large adenoma cells with abundant basophilic cytoplasm (hematoxylin-eosin, C), robust expression of ACTH (D) and a Ki-67 labelling index of 7\% (E); 400× magnification.

As the patient's clinical phenotype was compatible with CNC, mutation analysis of the PRKAR1A gene was undertaken. This revealed a previously described heterozygous germline mutation in exon 2 (c.109C $>$ T; p.Gln37Ter) that generates a premature stop codon (5), confirming the diagnosis of CNC in this patient. The mutation appeared to have occurred de novo, as confirmed by the lack of family history and negative genetic testing in the patient's parents. PRKAR1A, which encodes for the type 1 alpha regulatory subunit of the protein kinase A, has been suggested to act as a tumour suppressor gene driving tumorigenesis in CNC patients, as previously demonstrated by loss-of-heterozygosity studies (7). Thus, we extracted DNA from the pituitary tumour of our patient and performed loss-of-heterozygosity analysis. By Sanger sequencing, we found a partial loss of the wildtype allele at the level of the mutation in the patient's pituitary tumour (Fig. 2A). We then performed genotyping for two microsatellite markers (D17S942 - centromeric, and D17S789 - telomeric to PRKAR1A). While analysis of D17S942 was uninformative, genotyping for D17S789 confirmed the loss of the wild-type allele within the tumour (Fig. 2B), with an allele peak height ratio of 2.2, in keeping with loss-of-heterozygosity.

\section{Discussion}

$\mathrm{CNC}$ is a rare genetic syndrome with a variety of clinical manifestations $(2,3,4)$. Inactivating germline mutations of the PRKAR1A gene represent the most common cause of CNC. These mutations can be inherited in an autosomal dominant manner and disease penetrance is almost complete. However, only approximately $70 \%$ of $\mathrm{CNC}$ patients have a positive family history, whereas the remaining cases appear to be caused by de novo mutations $(3,5)$, as in our patient.

CNC patients can develop several endocrine manifestations, also including pituitary disease. The most common pituitary tumours in $\mathrm{CNC}$ are $\mathrm{GH}$ producing and sometimes co-secrete prolactin, whereas corticotroph adenomas have not been previously reported (11). While PRKAR1A mutations do not 
A

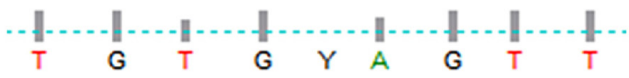

\section{blood}

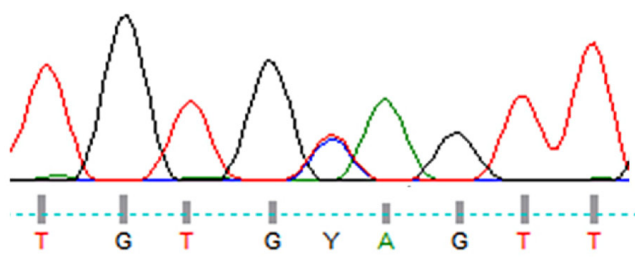

\section{tumour}

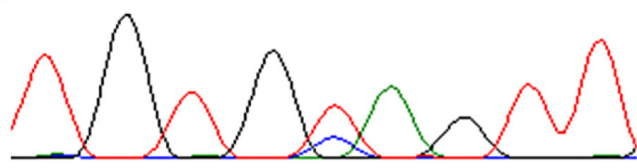

B
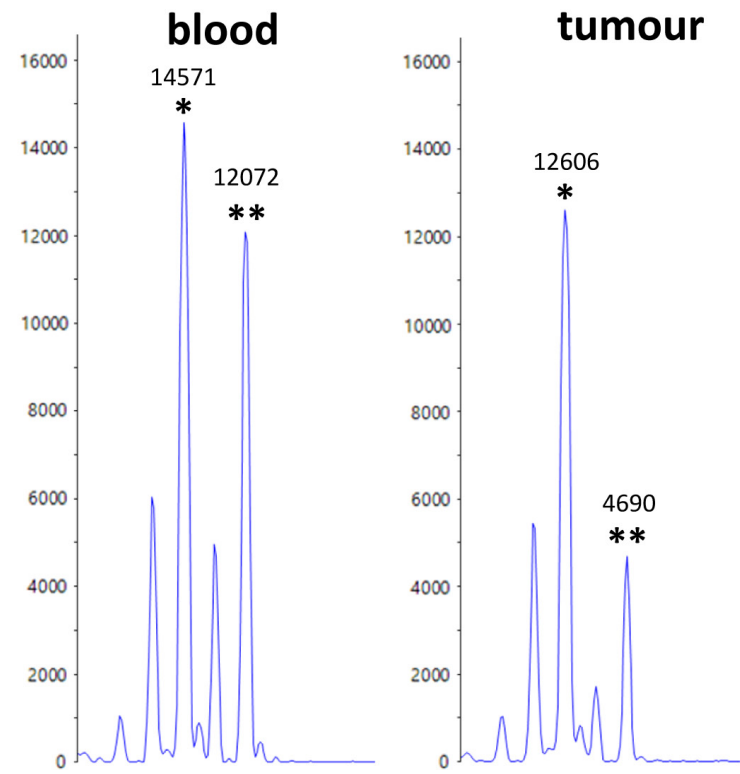

Figure 2

Sanger sequencing for the c.109C $>$ T PRKAR1A mutation and microsatellite genotyping show loss-of-heterozygosity in the corticotroph adenoma. (A) Sanger sequencing showed partial loss of the wild-type allele in the tumour sample, suggesting loss-of-heterozygosity. (B) Capillary electrophoresis analysis for the D17S789 microsatellite marker in blood- and tumourderived DNA, showing reduction of the wild-type $(* *)$ allele compared to the mutant (*) allele in the tumour sample. The ratio of allele peak heights was 2.2 , confirming the loss-ofheterozygosity.

typically lead to corticotroph adenomas, we need to keep in mind that $\mathrm{CRH}$ receptors type 1 and 2 signal through cAMP (12). In addition, at least one case of a corticotroph adenoma has been described with an activating mutation of GNAS, encoding the regulatory G-protein alpha subunit (13). Such mutations, leading to the constitutive activation of cAMP production, are responsible for McCune-Albright syndrome and represent common somatic mutations observed in somatotroph adenomas $(14,15)$.

Although loss of chromosome 17 has been described as one of the most common chromosomal alterations associated with corticotroph adenomas (16), mutations of the PRKAR1A gene have not been previously identified in patients with Cushing disease $(17,18)$. Our data support that the PRKAR1A mutation played a pathogenic role in the development of the pituitary corticotroph adenoma in this patient, as it is unlikely, although not entirely impossible, that, in addition to $\mathrm{CNC}$, this patient had a coincidental corticotroph adenoma with a somatic loss at the $17 \mathrm{q} 24$ locus.

While up to $60 \%$ of all CNC patients develop PPNAD and a significant proportion presents with clinically overt ACTH-independent Cushing syndrome $(2,4,5)$, to our knowledge, this is the first published case of a CNC patient with Cushing disease due to a corticotroph pituitary adenoma. In our patient, concomitant PPNAD as the reason for Cushing syndrome was ruled out on the basis of biochemistry and remission of Cushing syndrome after resection of the pituitary adenoma. In a previously reported case of a CNC patient with PPNAD, factitious elevation of ACTH levels has been described, possibly caused by interfering antibodies with ACTH-like activity (19). However, such possibility seems unlikely in our patient, considering the results of the IPS showing a significant central to peripheral ACTH ratio and the significant drop of the ACTH levels following transsphenoidal surgery. We are aware, however, that our patient has an increased risk for developing Cushing syndrome secondary to PPNAD during the course of his life, given the high frequency of PPNAD in patients with CNC.

In summary, we provide the first evidence that PRKAR1A loss-of-function mutations can be involved in the tumorigenesis of corticotroph pituitary adenomas. Hence, pituitary-dependent Cushing disease should be considered in the differential diagnosis of hypercortisolism in CNC patients.

\section{Methods}

\section{Histopathology and immunohistochemistry}

The tumour biopsy specimen was fixed in $4.5 \%$ neutral buffered formalin, embedded in paraffin, cut at $5 \mu \mathrm{m}$ and stained with haematoxylin and eosin. Immunohistochemistry was performed with a streptavidin-biotin-peroxidase complex method. Sections 
were stained with monoclonal antibodies for Ki-67 and ACTH (Dako, Agilent Technologies) using a Dako AutostainerPlus Link automated immunostainer (Agilent Technologies). For visualization the Envision FLEX Plus Dako kit (Agilent Technologies) was used according to the manufacturer's recommendations.

\section{Loss-of-heterozygosity studies}

Genomic DNA was isolated from the patient blood (Illustra DNA Extraction Kit BACC2, GE Healthcare) and pituitary corticotroph adenoma tissue (QIAamp DNA FFPE Tissue Kit, Qiagen). An amplicon encompassing the PRKAR1A c.109C $>\mathrm{T}$ mutation was amplified by PCR using the following primers: 5'-GCACGCAGCCTTCGAGAAT-3' (forward) and 5'-CTCCAACCTCTCAAAGTATTCCCTG-3' (reverse). The PCR products were sequenced by Sanger sequencing under standard conditions. Paired blood- and pituitary tumour-derived DNA samples were genotyped for two microsatellite markers, D17S942 (centromeric to PRKAR1A) and D17S789 (telomeric to PRKAR1A). The fluorescently tagged PCR products were run on an ABI3730xl (Applied Biosystems, Warrington, UK), and allele peak heights were measured using the Peak Scanner Software v1.0 (Applied Biosystems). The ratio of allele peak heights of the normal and tumour samples was calculated as follows: (peak height of normal allele 2/peak height of normal allele 1)/(peak height of tumour allele 2 /peak height of tumour allele 1 ). A value $<0.5$ or $>2$ was considered in keeping with loss-ofheterozygosity, as previously suggested (20).

\section{Declaration of interest}

The authors declare that there is no conflict of interest that could be perceived as prejudicing the impartiality of this case report.

\section{Funding}

This research did not receive any specific grant from any funding agency in the public, commercial or not-for-profit sector.

\section{Patient consent}

The patient's written informed consent was obtained for genetic studies and for publication of this manuscript.

\section{Author contribution statement}

F W K, Y W, S W, E K, F T, Mi Kr, A L and A G cared for the patient. D I and Má Ko performed the loss-of-heterozygosity studies. $\mathrm{R} \mathrm{H}$ performed the immunohistochemical analyses. F W K, A G, D I and Má Ko wrote the manuscript. All authors reviewed and edited the manuscript.

\section{Acknowledgements}

We acknowledge Dr Karen Stals (Molecular Genetics, Royal Devon and Exeter NHS Foundation Trust, Exeter, UK) for technical advice on the interpretation of microsatellite genotyping.

\section{References}

1 Rees JR, Ross FG \& Keen G. Lentiginosis and left atrial myxoma. British Heart Journal 197335 874-876. (doi:10.1136/hrt.35.8.874)

2 Carney JA, Gordon H, Carpenter PC, Shenoy BV \& Go VL. The complex of myxomas, spotty pigmentation, and endocrine overactivity. Medicine 198564 270-283. (doi:10.1097/00005792198507000-00007)

3 Stratakis CA, Kirschner LS \& Carney JA. Clinical and molecular features of the Carney complex: diagnostic criteria and recommendations for patient evaluation. Journal of Clinical Endocrinology and Metabolism 200186 4041-4046. (doi:10.1210/ jcem.86.9.7903)

4 Boikos SA \& Stratakis CA. Carney complex: pathology and molecular genetics. Neuroendocrinology 200683 189-199. (doi:10.1159/000095527)

5 Bertherat J, Horvath A, Groussin L, Grabar S, Boikos S, Cazabat L, Libe R, Rene-Corail F, Stergiopoulos S, Bourdeau I et al. Mutations in regulatory subunit type $1 \mathrm{~A}$ of cyclic adenosine 5 '-monophosphatedependent protein kinase (PRKAR1A): phenotype analysis in 353 patients and 80 different genotypes. Journal of Clinical Endocrinology and Metabolism 200994 2085-2091. (doi:10.1210/jc.2008-2333)

6 Shabb JB. Physiological substrates of cAMP-dependent protein kinase. Chemical Reviews 2001101 2381-2411. (doi:10.1021/cr0002361)

7 Kirschner LS, Carney JA, Pack SD, Taymans SE, Giatzakis C, Cho YS, Cho-Chung YS \& Stratakis CA. Mutations of the gene encoding the protein kinase A type I-alpha regulatory subunit in patients with the Carney complex. Nature Genetics 200026 89-92. (doi:10.1038/79238)

8 Horvath A, Bertherat J, Groussin L, Guillaud-Bataille M, Tsang K, Cazabat L, Libe R, Remmers E, Rene-Corail F, Faucz FR et al. Mutations and polymorphisms in the gene encoding regulatory subunit type 1-alpha of protein kinase A (PRKAR1A): an update. Human Mutations 201031 369-379. (doi:10.1002/humu.21178)

9 Kirschner LS. Use of mouse models to understand the molecular basis of tissue-specific tumorigenesis in the Carney complex. Journal of Internal Medicine 2009266 60-68. (doi:10.1111/j.13652796.2009.02114.x)

10 Correa R, Salpea P \& Stratakis CA. Carney complex: an update. European Journal of Endocrinology 2015173 M85-M97. (doi:10.1530/ EJE-15-0209)

11 Boikos SA \& Stratakis CA. Pituitary pathology in patients with Carney complex: growth-hormone producing hyperplasia or tumors and their association with other abnormalities. Pituitary 20069 203-209. (doi:10.1007/s11102-006-0265-2)

12 Grammatopoulos DK. Insights into mechanisms of corticotropinreleasing hormone receptor signal transduction. British Journal of Pharmacology 2012166 85-97. (doi:10.1111/j.14765381.2011.01631.x)

13 Riminucci M, Collins MT, Lala R, Corsi A, Matarazzo P, Gehron Robey P \& Bianco P. An R201H activating mutation of the GNAS1 (Gsalpha) gene in a corticotroph pituitary adenoma. Molecular Pathology 2002 55 58-60. (doi:10.1136/mp.55.1.58)

14 Weinstein LS, Shenker A, Gejman PV, Merino MJ, Friedman E \& Spiegel AM. Activating mutations of the stimulatory $G$ protein in the McCune-Albright syndrome. New England Journal of Medicine 1991 325 1688-1695. (doi:10.1056/nejm199112123252403)

15 Clementi E, Malgaretti N, Meldolesi J \& Taramelli R. A new constitutively activating mutation of the Gs protein alpha subunitgsp oncogene is found in human pituitary tumours. Oncogene 19905 1059-1061. 
16 Pack SD, Qin LX, Pak E, Wang Y, Ault DO, Mannan P, Jaikumar $\mathrm{S}$, Stratakis CA, Oldfield EH, Zhuang Z et al. Common genetic changes in hereditary and sporadic pituitary adenomas detected by comparative genomic hybridization. Genes, Chromosomes and Cancer 200543 72-82. (doi:10.1002/gcc.20162)

17 Kaltsas GA, Kola B, Borboli N, Morris DG, Gueorguiev M, Swords FM, Czirjak S, Kirschner LS, Stratakis CA, Korbonits M et al. Sequence analysis of the PRKAR1A gene in sporadic somatotroph and other pituitary tumours. Clinical Endocrinology 200257 443-448. (doi:10.1046/j.1365-2265.2002.01643.x)

18 Stratakis CA, Tichomirowa MA, Boikos S, Azevedo MF, Lodish M, Martari M, Verma S, Daly AF, Raygada M, Keil MF et al. The role of germline AIP, MEN1, PRKAR1A, CDKN1B and CDKN2C mutations in causing pituitary adenomas in a large cohort of children, adolescents, and patients with genetic syndromes. Clinical Genetics $2010 \mathbf{7 8}$ 457-463. (doi:10.1111/j.1399-0004.2010.01406.x)

19 Slyper AH \& Findling JW. Use of a two-site immunoradiometric assay to resolve a factitious elevation of ACTH in primary pigmented nodular adrenocortical disease. Journal of Pediatric Endocrinology 1994 7 61-63. (doi:10.1515/JPEM.1994.7.1.61)

20 Broeks A, Urbanus JH, Floore AN, Dahler EC, Klijn JG, Rutgers EJ, Devilee P, Russell NS, van Leeuwen FE \& van't Veer LJ. ATMheterozygous germline mutations contribute to breast cancersusceptibility. American Journal of Human Genetics $20006 \mathbf{6}$ 494-500.

Received 18 March 2017

Revised version received 26 April 2017

Accepted 18 May 2017 